\title{
Transparent Hose Has the Advantages of Reducing Surgical Trauma and Complications in the Treatment of Benign Pros- tatic Hyperplasia Patients with Bladder Stones
}

\author{
YUN FU, SHIHUA YU ${ }^{1}$, YUCHUAN JIANG ${ }^{2}$ AND XINGJING LONG ${ }^{*}$
}

Department of Urology Surgery, Chongqing High-tech Zone People's Hospital, 'Department of Urology Surgery, Traditional Chinese Medicine Hospital, Tongliang, ${ }^{2}$ Internal/General Medicine, Chongqing High-tech Zone People's Hospital, ${ }^{3}$ Department of General Surgery, Chongqing High-Tech Zone People's Hospital, Chongqing, China

Fu et al.: Clinical Effect of Transparent Hose in the Treatment of Benign Prostatic Hyperplasia To investigate the clinical effect of transparent hose in the treatment of benign prostatic hyperplasia with bladder stones by transurethral resection of prostate. A total of 130 benign prostatic hyperplasia patients with bladder calculi were selected and divided into the experimental group and the control group with 65 cases in each group. Both groups were treated with transurethral resection of the prostate. The experimental group was treated with transparent hose for bladder stones and the control group was treated with transurethral resection of the prostate and cystoscopy. The operation and postoperative related indexes of the two groups were compared and analyzed. The operation time, blood loss, stone removal time and postoperative bladder irrigation time of the experimental group were lower than those of the control group and the difference was statistically significant $(\mathbf{p}<0.05)$. The International prostate symptom score, International index of erectile function-5 score, maximum urinary flow rate and residual urine volume values were evaluated before operation and $3 \mathrm{mo}$ after operation, respectively. There was no significant difference between the experimental group and the control group ( $>>0.05)$. The International prostate symptom score and residual urine volume measurement of the two groups at $3 \mathrm{mo}$ after operation were significantly lower than those before operation $(p<0.05)$ and the International index of erectile function-5 score was significantly higher than that before operation $(p<0.05)$. The experimental group had lower postoperative complication rate as $4.62 \%$ than $16.92 \%$ in the control group and the difference was statistically significant $(\mathbf{p}<\mathbf{0 . 0 5})$. The use of transparent hoses in prostatectomy for patients with benign prostatic hyperplasia with bladder stones can shorten the operation time, reduce intraoperative bleeding, accelerate postoperative recovery and reduce surgical complications.

Key words: Prostatectomy, benign prostatic hyperplasia, bladder stones

Benign prostatic hyperplasia $(\mathrm{BPH})^{[1]}$ is a common clinical benign prostatic disease. Bladder stone is one of the common complications of $\mathrm{BPH}$ and it is a common cause of urinary dysfunction in middle-aged and elderly men. At present, transurethral endoscopic lithotripsy combined with cyst by transurethral endoscopic lithotripsy combined with cystoscope sheath or transurethral resection of cystoscope sheath. However, the traditional cystoscope sheath is a metal pipe, which is opaque and the design of lip-shaped notch in the front of the cystoscope sheath affects the overall vision. There is a certain blind area of vision in the operation, which not only affects the work efficiency, but also increases the risk of by repeatedly inserting, exiting and rotating the cystoscope sheath when changing the vision and operating devices, especially when the stones are large ${ }^{[2]}$. Some studies have improved the transurethral resection of the prostate sheath and cystoscope sheath assisted stone extraction and replaced cystoscope sheath with transparent hose. Due to the transparency of the hose, the scope of endoscopic observation can be expanded during the operation, which is conducive to the rapid and accurate judgment of the location of the stone and helps to accurate operation and greatly reduces the risks of urethral injury, bladder perforation, residual stone, and

*Address for correspondence

E-mail: Longxingjing@126.com 
postoperative infection ${ }^{[3]}$. However, there are few studies on whether there is an advantage in the influence of surgical effect and postoperative erectile function. This study explored the clinical application value of transparent hose in the treatment of BPH patients with bladder stones by transurethral resection of the prostate, which is reported as follows. A total of $130 \mathrm{BPH}$ patients with bladder stones admitted to our hospital were selected for clinical research. They were randomly divided into the experimental group and the control group with 65 cases in each group. The study subjects were selected from August 2016 to February 2019. Inclusion criteria-BPH, bladder stones in the diagnosis of reference to the people's health press (Endourology) [4] in the 3rd edition of the standard; Patients were confirmed by computed tomography (CT) urography, urinary system X-ray and ultrasound; Patients aged 19$79 \mathrm{y}$; Bladder stone diameter $>2.0 \mathrm{~cm}$; This study met the requirements of the Medical Ethics Committee and signed an informed consent form with the patient himself before treatment. Exclusion criteria-Malignant tumor; Bladder outlet obstruction, neurogenic bladder and other diseases; stricture, deformity, scar formation after previous surgery; Mental illness, mental retardation; blood system diseases; Other surgical contraindications. The experimental group, aged 54 79 $\mathrm{y}$, average $66.3 \pm 5.6 \mathrm{y}$; the maximum diameter of bladder stones was $2.8 \sim 5.8 \mathrm{~cm}$, mean $4.3 \pm 0.9 \mathrm{~cm}$. Number of stones: single 27 cases, multiple 38 cases; prostate volume: $68.2 \pm 14.3 \mathrm{~mL}$; The International prostate symptom score (IPSS) of preoperative patients was $28.2 \pm 3.0$. Control group, age $56 \sim 79$ y old, average $65.5 \pm 5.1$ y old; The maximum diameter of bladder stones was $2.5 \sim 6.1 \mathrm{~cm}$ mean $4.4 \pm 1.1 \mathrm{~cm}$. Number of stones: single 32 cases, multiple 33 cases; prostate volume $66.4 \pm 10.0 \mathrm{~mL}$; IPSS of preoperative patients was $27.4 \pm 4.1$. There was no significant difference in the above baseline data between the two groups $(\mathrm{p}>0.05)$, See Table 1 for details. The patients in the two groups were subjected to surgery under continuous epidural anesthesia, and the lithotomy position was taken. The control group was treated with transurethral resection of the prostate outer sheath and cystoscopy outer sheath. Surgical instruments: resectoscope (Carol, UK) and nephroscope (Wolf, Germany). The resectoscope was placed into the bladder under direct vision to observe the situation in the bladder. Retain the outer sheath and remove the resectoscope. Place nephroscope and inject sterile saline into bladder. Lithotripsy and stone extraction were performed through the nephroscope channel. The experimental group was treated with transparent hose for bladder calculi. The $18 \mathrm{~F}$ transparent hose was inserted outside the sheath of the mirror and the working channel of the electrotomy mirror was inserted. The $2-3 \mathrm{~cm}$ outside the sheath of the electrotomy mirror was extended and the transparent hose channel was used as the working channel. The gravel operation is the same as above. During the same period, the two groups were treated with transurethral resection of the prostate. The urethra was examined comprehensively and the electrotomy mirror was inserted to find the essence. The groove was cut out and the bilateral and middle lobes were removed successively. The operation time, blood loss, stone extraction time, postoperative bladder irrigation time, extubation time and hospitalization time of the two groups were observed and compared. The international prostate symptom score (IPSS) ${ }^{[5]}$, international erectile function score (IIEF-5) score ${ }^{[6]}$, maximum urinary flow rate (Qmax) and residual urine volume (RUV) before and after treatment were compared between the two groups. The International Erectile Function Score (IIEF-5) mainly includes the following five aspects: How much confidence does it have in penis erection and erection maintenance? How many times can the penis be erectile and successfully inserted into the vagina after stimulation? How many times does sexual intercourse have the penis inserted into the vagina and maintained erection? How difficult is it to maintain penile erection until the end of sexual intercourse? Do you feel satisfied when trying to have sex? The total score was 25 points. Patients with erectile dysfunction were less than 21 points. In this study, Statistical package for the social sciences (SPSS) 21.0 software was used to complete the relevant statistical analysis after the data were collected and sorted out. The measurement data such as IIEF-5 score and IPSS score of the two groups were expressed as $\left(\chi^{2} \pm s\right)$, and t test was used for comparison between groups. $\chi^{2}$ test was used to compare the count data such as complication rate; $\mathrm{p}<0.05$ indicated that the difference was statistically significant. The operation time, the amount of bleeding, the time of taking stone and the time of bladder washing after operation in the test group were lower than those in the control group $(p<0.05)$; there was no significant difference in extubation time and hospitalization time between the test group and the control group ( $>0.05)$; See Table 2. The IPSS score, IIEF-5 score, Qmax and RUV measured values of the experimental group and the control group were compared before operation and 3 mo after operation and the differences were not statistically significant ( $>0.05$ ). The IPSS score and 
RVU measurement of the two groups at 3 mo after operation were significantly lower than those before operation $(p<0.05)$ and the IIEF-5 score was significantly higher than that before operation $(\mathrm{p}<0.05)$ see Table 3. After operation, the complication rate of the experimental group was $4.62 \%$ lower than that of the control group $(p>0.05)$; See Table 4 . BPH with bladder stones are common in clinical work. Transurethral resection of prostate is the gold standard for the treatment of BPH. In the treatment of BPH with bladder stones, lithotripsy or stone removal should be performed simultaneously in transurethral resection of prostate ${ }^{[7]}$.The traditional cystolithotomy has great trauma and poor acceptance. In recent years, with the rapid development of endoscopic surgery in urology, most patients can achieve good lithotripsy effect after transurethral endoscopic treatment ${ }^{[8]}$. However, the current endoscopic treatment of $\mathrm{BPH}$ with bladder stones is not perfect. Since the traditional cystoscopy sheath and prostate electrocision sheath are metal materials, they are opaque and have blind field outside the sheath, which will seriously affect the work efficiency ${ }^{[9]}$. Since the stones are easy to roll in the process of lithotripsy and the broken stones are easy to drift to hidden positions such as bladder folds and diverticulum, it is difficult for surgeons to quickly and accurately capture the residual stones, resulting in long time consuming and low efficiency of lithotripsy. If intraoperative insertion, exit, rotation of the mirror sheath caused some damage to the urethra, increase the risk of surgery ${ }^{[10]}$. If the lithotripsy time is prolonged, it is easy to cause bladder mucosa edema and brittleness, which increases the risk of intraoperative bladder perforation and postoperative infection ${ }^{[11]}$. In particular, for patients with cardiopulmonary basic diseases, the extension of operation time will increase the risk of operation. Some patients need to undergo and the operation risk and cost increase, which is also easy to cause doctor-patient conflicts ${ }^{[12]}$. In this study, in view of the defects of the traditional cystoscope sheath and the external sheath of the prostate electrotomy mirror affecting the field of vision, the transparent hose lithotripsy was applied in the sheath and good results were achieved. The operation time, blood loss, stone removal time and postoperative bladder irrigation time of the patients treated with transparent hose were lower than those of the patients treated with transurethral resection of prostate sheath and cystoscopy sheath. The extubation time and hospitalization time of the two groups were similar. This is because the hose is transparent, can expand the scope of endoscopic vision, is conducive to the surgeon quickly and accurately determine and lock the location of stones, more conducive to accurate operation, so the use of transparent hose assisted stone extraction can reduce the difficulty of surgery, shorten the operation time, stone extraction time, postoperative bladder irrigation time and reduce surgical trauma, reduce blood loss ${ }^{[13]}$. In this study, the urination symptoms and erectile function of the patients were evaluated at 3 mo after operation. It was found that the IPSS score and RUV measured value of the two groups were significantly lower than those before operation and the IIEF-5 score was significantly higher than that before operation, but there was no significant difference between the two groups at 3 mo after operation. This result suggests that transurethral resection of the prostate combined with stone extraction has a good effect in the treatment of BPH with bladder stones, which can effectively improve the urination symptoms and erectile function of patients. Transparent hose-assisted lithotripsy did not significantly improve the urination symptoms and erectile function of patients. This may be because the improvement of micturition symptoms and erectile function of patients is related to the surgical effect of transurethral resection of the prostate and the use of transparent hose has no effect on transurethral resection of the prostate ${ }^{[14-16]}$. Postoperative follow-up showed that the risk of postoperative complications such as urethral injury, bladder perforation, postoperative infection and residual stones in patients with transparent hose-assisted lithotripsy was lower than that in patients with transurethral resection of prostate sheath and cystoscopy sheath-assisted lithotripsy. This is because the diameter of the transparent hose is $18 \mathrm{~F}$ and the joint working channel is suitable after the nephroscope is inserted. This is because the diameter of the transparent hose is $18 \mathrm{~F}$ and the joint working channel is suitable after the nephroscope is inserted. The diameter of the external sheath of the transurethral resection of prostate is 26 Fr. The larger diameters makes the bladder perfusion fluid loss too fast, the bladder is empty, the bladder mucosal fold is excessive and the bladder stones are hidden in the fold, which makes it difficult for the surgeon to find gravel and leads to residual stones. Small working channel can lead to excessive bladder filling, bladder wall thinning, easy to damage perforation. The tube of transparent hose is soft and has little damage to the urethra and bladder, which is conducive to reducing iatrogenic injury and increasing surgical safety ${ }^{[17-19]}$. The surgical treatment of BPH with bladder calculi can reduce surgical trauma and 
accelerate the rehabilitation of patients if bladder calculi can be treated simultaneously with transurethral resection of prostate. However, due to the opacity of the traditional cystoscopy sheath and the outer sheath of the prostate electrotomy mirror, the blind area of the intraoperative visual field is not conducive to the simultaneous implementation of the two surgeries, which increases the difficulty of surgery.In this study, transparent hose was used to solve this problem, which greatly reduced the difficulty of dealing with bladder stones at the same time of transurethral resection of the prostate. It had certain advantages in shortening the operation time, reducing intraoperative bleeding, accelerating postoperative recovery and reducing surgical complications. At the same time, it did not affect the improvement of urination symptoms and erectile function of patients, which was worthy of clinical application. In summary, the application of transparent hose in the treatment of $\mathrm{BPH}$ patients with bladder stones has the effects of shortening operation time, reducing intraoperative bleeding, accelerating postoperative recovery and reducing surgical complications.

TABLE 1: COMPARISON OF BASELINE DATA OF TWO GROUPS OF RESEARCH OBJECTS

\begin{tabular}{|c|c|c|c|c|c|c|c|}
\hline \multirow{2}{*}{ Group } & \multirow{2}{*}{$\mathrm{n}$} & \multirow{2}{*}{ Age $(y)$} & \multirow{2}{*}{$\begin{array}{l}\text { Maximum } \\
\text { diameter of } \\
\text { stone }(\mathrm{cm})\end{array}$} & \multicolumn{2}{|c|}{ Number of stones } & \multirow{2}{*}{$\begin{array}{c}\text { Prostate } \\
\text { volume }(\mathrm{mL})\end{array}$} & \multirow{2}{*}{$\begin{array}{c}\text { IPSS score } \\
\text { (points) }\end{array}$} \\
\hline & & & & Single & Multi & & \\
\hline $\begin{array}{l}\text { Observation } \\
\text { group }\end{array}$ & 65 & $66.3 \pm 5.6$ & $4.3 \pm 0.9$ & 27 & 38 & $68.2 \pm 14.3$ & $28.2 \pm 3.0$ \\
\hline Matched group & 65 & $65.5 \pm 5.1$ & $4.4 \pm 1.1$ & 32 & 33 & $66.4 \pm 10.0$ & $27.4 \pm 4.1$ \\
\hline$t / \chi^{2}$ & & 0.852 & -0.567 & 0.776 & 0.832 & 1.270 & $\mathrm{p}$ \\
\hline $\mathrm{p}$ & & 0.396 & 0.572 & 0.378 & 0.407 & 0.207 & \\
\hline
\end{tabular}

TABLE 2: ANALYSIS OF SURGICAL AND POSTOPERATIVE TWO GROUPS $\left(\chi^{2} \pm s\right)$

\begin{tabular}{|c|c|c|c|c|c|c|c|}
\hline Group & $n$ & $\begin{array}{l}\text { Operation } \\
\text { time (min) }\end{array}$ & $\begin{array}{c}\text { Surgical } \\
\text { bleeding }(\mathrm{mL})\end{array}$ & $\begin{array}{l}\text { Time to take } \\
\text { stone (min) }\end{array}$ & $\begin{array}{l}\text { Bladder } \\
\text { irrigation } \\
\text { time }(\mathrm{h})\end{array}$ & $\begin{array}{l}\text { Extubation } \\
\text { time (d) }\end{array}$ & $\begin{array}{l}\text { Length of } \\
\text { stay (d) }\end{array}$ \\
\hline $\begin{array}{l}\text { Observation } \\
\text { group }\end{array}$ & 65 & $134.9 \pm 18.0$ & $81.3 \pm 27.6$ & $29.6 \pm 7.4$ & $48.1 \pm 8.5$ & $5.2 \pm 1.0$ & $6.3 \pm 1.2$ \\
\hline Matched group & 65 & $158.0 \pm 22.1$ & $108.0 \pm 30.1$ & $45.0 \pm 9.8$ & $52.3 \pm 9.4$ & $5.4 \pm 1.3$ & $6.7 \pm 1.5$ \\
\hline $\mathrm{T}$ & & -6.534 & -5.271 & -10.111 & -2.672 & -0.983 & -1.679 \\
\hline$p$ & & 0.000 & 0.000 & 0.000 & 0.009 & 0.327 & 0.096 \\
\hline
\end{tabular}

TABLE 3: CHANGES OF IPSS SCORE, SEXUAL FUNCTION AND URINARY FUNCTION BEFORE AND AFTER OPERATION IN TWO GROUPS $\left(\chi^{2} \pm s\right)$

\begin{tabular}{|c|c|c|c|c|c|c|c|c|c|}
\hline \multirow[b]{2}{*}{ Group } & \multirow[b]{2}{*}{$\mathrm{n}$} & \multicolumn{2}{|c|}{ IPSS score (points) } & \multicolumn{2}{|c|}{ IIEF-5 score (points) } & \multicolumn{2}{|c|}{ Qmax (mL/s) } & \multicolumn{2}{|c|}{$\mathrm{RVU}(\mathrm{mL})$} \\
\hline & & Preoperative & $\begin{array}{l}3 \text { mo after } \\
\text { operation }\end{array}$ & Preoperative & $\begin{array}{c}3 \text { mo after } \\
\text { operation }\end{array}$ & Preoperative & $\begin{array}{l}3 \text { mo after } \\
\text { operation }\end{array}$ & Preoperative & $\begin{array}{c}3 \text { mo after } \\
\text { operation }\end{array}$ \\
\hline $\begin{array}{l}\text { Observation } \\
\text { group }\end{array}$ & 65 & $28.2 \pm 3.0$ & $5.1 \pm 1.4^{*}$ & $22.3 \pm 2.9$ & $22.7 \pm 3.0$ & $8.04 \pm 2.11$ & $19.63 \pm 3.28^{*}$ & $98.7 \pm 12.8$ & $10.3 \pm 3.0^{*}$ \\
\hline $\begin{array}{l}\text { Matched } \\
\text { group }\end{array}$ & 65 & $27.4 \pm 4.1$ & $5.4 \pm 1.7^{*}$ & $21.8 \pm 4.1$ & $22.2 \pm 3.2$ & $8.44 \pm 2.31$ & $19.21 \pm 3.05^{*}$ & $101.4 \pm 16.5$ & $11.4 \pm 3.8^{*}$ \\
\hline $\mathrm{t}$ & & 1.27 & -1.098 & 0.803 & 0.919 & -1.031 & 0.756 & -1.042 & -1.832 \\
\hline$p$ & & 0.207 & 0.274 & 0.424 & 0.36 & 0.305 & 0.451 & 0.299 & 0.069 \\
\hline
\end{tabular}

Note: Comparison with this group before operation; * $p<0.05$ 
www.ijpsonline.com

TABLE 4: COMPARISON OF SURGICAL COMPLICATIONS BETWEEN THE TWO GROUPS

\begin{tabular}{lcccccc}
\hline Group & $\mathrm{n}$ & Urethral injury & Perforating & $\begin{array}{c}\text { Postoperative } \\
\text { infection }\end{array}$ & $\begin{array}{c}\text { Stone residue } \\
\text { Complications } \\
(\%)\end{array}$ \\
\hline $\begin{array}{l}\text { Observation } \\
\text { group }\end{array}$ & 65 & 0 & 0 & 3 & 0 & $3(4.62)$ \\
Matched group & 65 & 3 & 1 & 6 & 1 & $11(16.92)$ \\
$\chi^{2}$ & & & & & 5.123 \\
$\mathrm{p}$ & & & & & 0.024 \\
\hline
\end{tabular}

\section{Conflict of interests:}

The authors declared no conflicts of interest.

\section{REFERENCES}

1. Xu H, Cai Z, Chen Y, Gu M, Chen Q, Wang Z. Benign prostatic hyperplasia surgical scoring (BPHSS): a novel scoring system for the perioperative outcomes of holmium laser enucleation of the prostate. Lasers Med Sci 2018;33(3):589-95.

2. Inage K, Mizusawa H, Mimura Y, Shimizu F. Patient with inguinal hernia containing the urinary bladder complicated by bladder stones. IJU Case Reports 2019;2(5):276-8.

3. Vince R, Hampton LJ, Vartolomei MD, Shariat SF, Porpiglia F, Autorino R. Robotic assisted simple prostatectomy: recent advances. Curr Opin Urol 2018;28(3):309-14.

4. Smith AD, Badlani GH, Bagley DH, Guo Y, Li X. Smith Endovascular urology. Beijing People's Health Publishing House 2011:126.

5. Cao H, Gui S. Determination of urinary flow rate and international prostate symptom score in patients with prostatic hyperplasia. Chin J Gerontol 2010;30(16):2377-8.

6. Raina R, Ausmundson S, Saleh RA, Agarwal A, Lakin MM, Zippe CD. Muse therapy for erectile dysfunction (ED) after radical prostatectomy (RP): SHIM (IIEF-5) analysis. Fertil Steril 2002;78(1):S211.

7. Anderson BB, Heiman J, Large T, Lingeman J, Krambeck A. Trends and perioperative outcomes across major benign prostatic hyperplasia procedures from the ACS-NSQIP 20112015. J Endourol 2019;33(1):62-8.

8. Kar A, Gulati S, Mohammed S, Valappil MV, Sarala BB, Ghatak $\mathrm{S}$, et al. Surgical management of cystic duct stump stone or gall bladder remnant stone. Indian J Surg 2018;80(3):284-7.

9. Jung JH, Park J, Kim WT, Kim HW, Kim HJ, Hong S, et al. The association of benign prostatic hyperplasia with lower urinary tract stones in adult men: A retrospective multicenter study. Asian J Urol 2018;5(2):118-21.

10. Foster HE, Dahm P, Kohler TS, Lerner LB, Parsons JK, Wilt TJ, et al. Surgical Management of Lower Urinary Tract Symptoms Attributed to Benign Prostatic Hyperplasia: AUA Guideline Amendment 2019. J Urol 2019;202(3):593-9.
11. Rahman MM, Johura FT, Rasul MA, Bhuiyan AK, Ali MI, Hossain MS, et al. Effect of Preoperative Dutasteride on Bleeding Related to Transurethral Resection of Prostate in Patients with Benign Prostatic Hyperplasia. J Biosci Med 2019;7(05):157-9.

12. Ferhatoglu MF, Kivilcim T, Kartal A, Filiz AI. A rare pathology mimicking the gallstone: heterotopic pancreas in the gallbladder. Cureus 2018;10(5):325-9.

13. Kang PM, Kim YJ, Seo WT, Kang SH, Kim TS, Chun BK, et $a l$. Correlation between $5-\alpha$ reductase type 2 protein expression and methylation of 5- $\alpha$ reductase type 2 promotor gene of benign prostatic hyperplasia. World J Urol 2019;37(4):709-18.

14. Lee YJ, Oh SJ. Calculi in the Prostatic Surgical Bed as a complication after Holmium Laser Enucleation of the Prostate. Urol J 2018;15(5):238-41.

15. Villa L, Capogrosso P, Capitanio U, Martini A, Briganti A, Salonia A, et al. Silodosin: an update on efficacy, safety and clinical indications in urology. Adv Ther 2019;36(1):1-8.

16. Yunusa B, Cassell A, Konneh S, Sheriff S, Ikpi E. The Outcome of Transvesical Prostatectomy-A Multicenter Retrospective Study. Open J Urol 2019;9(05):85-92.

17. Sperling DS, Farbstein A, Farbstein S, Gentile JC. Early functional outcomes following in-bore transrectal MR imageguided focal laser ablation for men with benign prostatic hyperplasia at one year. Acta radiol 2019;60(10):1367-71.

18. Insausti I, de Ocáriz AS, Galbete A, Capdevila F, Solchaga $\mathrm{S}$, Giral P, et al. Randomized comparison of prostatic artery embolization versus transurethral resection of the prostate for treatment of benign prostatic hyperplasia. J Vasc Interv Radiol 2020;31(6):882-90.

19. Saddam HH, Kumar JS, Bhushan SC. Efficacy of Bladder Neck Incision (BNI) Versus Transurethral Resection of Prostate (TURP) in Management of Benign Prostatic Hyperplasia (BPH) Causing Obstruction: A Randomised Controlled Study. Open J Urol 2019;9(8):119-29.

This is an open access article distributed under the terms of the Creative Commons Attribution-NonCommercial-ShareAlike 3.0 License, which allows others to remix, tweak, and build upon the work non-commercially, as long as the author is credited and the new creations are licensed under the identical terms

This article was originally published in a special issue,
"Therapeutic Perspectives in Biomedical Research and Pharma-
ceutical Sciences and their Nursing Methods"
Indian J Pharm Sci 2021:83(4)Spl issue "22-26"

